\title{
Adaptation and Validation of the Brazilian Version of the Fear of COVID-19 Scale
}

\author{
Francisco Roberto Sanchez Cavalheiro ${ }^{1,2}$ (D) Marina Greghi Sticca ${ }^{1}$ (D)
}

Accepted: 16 October 2020 / Published online: 23 November 2020

(C) Springer Science+Business Media, LLC, part of Springer Nature 2020

\begin{abstract}
The pandemic caused by COVID-19 has generated psychological impacts, such as fear of this disease. The authors developed the Fear of COVID-19 Scale (FCV-19S), which aims to assess the fear of COVID-19 in the general population. Adapt and validate the FCV19S for the Portuguese language in the Brazilian context. Four main initial steps were performed: translation, back-translation, semantic validation, and experimental application. Snowball sampling corresponded to 354 Brazilian participants. Psychometric tests were performed to investigate the validity and reliability of the test, such as confirmatory factor analysis (CFA). Analysis of the data showed satisfactory internal consistency ( $\alpha=$ 0.88 ), and CFA (factor loads from 0.57 to 0.86 ) confirmed the unidimensional structure. The Brazilian version of FCV-19S is considered valid, reliable, and appropriate for application among the general Brazilian population and may contribute to the prevention, treatments, and mental health programs, resulting from the pandemic of COVID-19.
\end{abstract}

Keywords Fear $\cdot$ COVID-19 $\cdot$ Coronavirus $\cdot$ SARS-CoV-2 $\cdot$ Pandemic $\cdot$ Fear of COVID-19 Scale

The COVID-19 pandemic has caused a parallel epidemic of fear (Yao et al. 2020). According to data published on the website of the Ministry of Health of Brazil, on June 21, 2020, at $18: 45$, this country accumulated 1,085,038 confirmed cases of COVID-19, of which 50,617 corresponded to confirmed deaths (lethality rate $=4.7 \%$ ), 549,386 relate to recovered cases, and 485,035 correspond to cases being monitored, with an incidence of 516.3 and mortality of 24.1, both for every 100 thousand inhabitants (Ministry of Health of Brazil 2020). At the time, Brazil was the second country with the most confirmed cases and deaths by COVID-19, just behind the USA (Johns Hopkins University 2020).

Patients with confirmation or suspicion of being infected with the coronavirus (SARS$\mathrm{CoV}-2)$ may be afraid of the consequences of the potentially fatal disease, as well as health

Francisco Roberto Sanchez Cavalheiro

franciscocavalheiro@gmail.com

1 Department of Psychology, University of São Paulo, Ribeirão Preto, SP, Brazil

2 Campinas, Brazil 
professionals, who may also experience the fear of contagion and spread the virus to their families, friends, or colleagues (Xiang et al. 2020b). In contexts of biological disasters, fear, uncertainty, and stigmatisation are common and can act as barriers to appropriate medical and mental health interventions (Xiang et al. 2020a). Doubtful or even false information about the factors related to the transmission of the virus, the incubation period, its geographical reach, the number of infected, and the actual mortality rate led to insecurity and fear in the population (Ornell et al. 2020). In addition, the fear of COVID-19 was considered a predictor of positive behaviour change (for example, social distance, better hand hygiene) and was related to decreased physical and environmental well-being (Harper et al. 2020).

Ethologists define fear as an emotional response triggered by specific "real", "external", "known", or "objective" stimuli, which give rise to defensive or escape behaviours, whereas anxiety can be understood as a response to a widespread threat, to an unknown threat, or to an internal conflict; thus, it presents the basic aspect of uncertainty (Steimer 2002; Strongman 1996). Therefore, anxiety can be characterised as a state of helplessness due to the perception of the inability to predict, control, or obtain desired results in certain personally important situations or contexts - it concerns a feeling of uncontrollability focused mainly on possible future threats or dangers or other potentially negative events to come, in contrast to fear, which occurs when danger is present or imminent, when people are directly threatened by a dangerous event, representing an alarm that mobilises them physically and cognitively for quick actions and, sometimes, superhuman efforts (Barlow 2000). Fear is a fundamental defence mechanism for survival and involves several biological processes to prepare for a response to potentially threatening events. (Ornell et al. 2020).

One psychological aspect of the COVID-19 pandemic is fear, and it is important to access it, so prevention and education programs can be developed according to socio-demographic groups (Pakpour and Griffiths 2020). Based on this, the Fear of COVID-19 Scale (FCV-19S) was developed by Ahorsu et al. (2020) in order to complement clinical efforts in preventing the spread and treatment of COVID-19 cases. This instrument can help researchers to assess the level of fear among populations during the COVID-19 pandemic (Pakpour and Griffiths 2020). The sample consisted of 717 Iranian participants, with a mean age equivalent to 31.25 years $(\mathrm{SD}=12.68)$, with more than half declaring themselves to be male $(n=416$; $58 \%$ ) (Ahorsu et al. 2020). The final scale consisted of seven items with factorial loads ranging from 0.66 to 0.74 , and the communalities were from 0.38 to 0.55 , with an average explained variance of $51 \%$ and Cronbach's alpha $(\alpha)$ of 0.82 (Ahorsu et al. 2020).

Bitan et al. (2020) evaluated the psychometric properties of the Hebrew version of FCV19S, applying it to 649 participants, of which $84.5 \%(n=540)$ declared themselves to be female, $30.5 \%(n=195)$ were 30 years old or less, 33.2\% $(n=212)$ were between 31 and 40 years old, and $36.3 \%(n=231)$ were 41 years old or more. The authors performed an exploratory factor analysis using varimax rotation, resulting in a unidimensional instrument, whose factor loads varied from 0.57 to 0.82 , with Cronbach's alpha of 0.86 , explaining $53.71 \%$ of the total variance (Bitan et al. 2020).

Reznik et al. (2020) performed an adaptation of the scale, using the translation and backtranslation method, and applied it to 850 participants from two Eastern European countries: Russia $(n=574 ; 67.5 \%)$ and Belarus $(n=276 ; 32.5 \%)$, with $73.2 \%(n=622)$ declaring themselves to be female, with an average age of 34.8 years $(\mathrm{SD}=13)$. The instrument had a satisfactory measure of internal consistency $(\alpha=0.809)$ and, after analysis of main components and varimax rotation, the factorial loads of the items varied from 0.569 to 0.841 , resulting in two factors: physiological responses to COVID-19 (items 3, 6, and 7) and 
emotional responses to COVID-19 (items 1, 2, 4, and 5), responsible for about 51\% and 47\%, respectively, of the variance of the total data (Reznik et al. 2020),

In Italy, the instrument was adapted and applied by Soraci et al. (2020) in 249 Italian participants, $92 \%(n=229)$ of whom declared themselves to be female, with an average age of 34.5 years $(\mathrm{SD}=12.21)$. This version also showed satisfactory internal consistency $(\alpha=$ 0.871 ), with factorial loads of items ranging from 0.688 to 0.897 , resulting in a unidimensional scale (Soraci et al. 2020). In Turkey, Satici et al. (2020) adapted and applied the scale to a sample of 1304 participants, $70.3 \%(n=917)$ of whom declared themselves to be female, with an average age of $29.47(\mathrm{SD}=10.54)$. The factorial loads of this Turkish version were significant, ranging from 0.484 to 0.723 , resulting in a unidimensional scale with satisfactory Cronbach's alpha $(\alpha=0.847)$, confirming the instrument's internal consistency (Satici et al. 2020). In Bangladesh, Sakib et al. (2020) adapted the scale and applied it to 8550 participants, of which $56 \%(n=4790)$ declared themselves to be male, with an average age of 26.53 years $(\mathrm{SD}=9.09)$, resulting in a unidimensional scale, with factor loads that ranged from 0.72 to 0.80 , and satisfactory internal consistency $(\alpha=0.871)$ (Sakib et al. 2020). The Arabic version of FCV-19S was applied to 639 participants from Saudi Arabia, with 57.9\% $(n=370)$ identifying themselves as male, with an average age of 34.75 years $(\mathrm{SD}=11.80)$, whose results corroborated the previous ones, presenting satisfactory internal consistency $(\alpha=0.88)$ and factorial loads that varied from 0.62 to 0.84 (Alyami et al. 2020). The Greek version of FCV-19S was applied to 2970 Greek participants, of which $72.5 \%(n=2153)$ declared themselves to be female, with $52 \%$ of the total sample belonging to the age group of 18 to 30 years, corroborating the previous results $(\alpha=0.87)$ and satisfactory factor loads in the confirmatory factor analysis (CFA) (from 0.45 to 0.92 ) (Tsipropoulou et al. 2020).

However, there is still no study adapting and validating the Fear of COVID-19 Scale for Brazil. Therefore, in order to fill this gap and complement previous results, this study had two main objectives: (1) to adapt and validate this instrument for the Portuguese language, in the Brazilian context, ascertaining the psychometric properties for this population, and (2) to analyse the factorial structure of the instrument.

\section{Methods}

\section{Participants}

Comrey (1988) suggests that a sample size of 200 participants is reasonably good for common factor analytical work with 40 or fewer variables. Clarke and Watson (1995) and Guadagnoli and Velicer (1988) recommend a sample size of at least 300 participants. Based on this, a total of 354 Brazilian participants who volunteered by the snowball sampling method were included in this study, with $59.9 \%$ from the state of São Paulo, $4.8 \%$ from Paraná, $4.2 \%$ from Santa Catarina, 2.3\% from Rio Grande do Sul, and 28.8\% from Brazilian locations not informed. The sample consisted of people of both sexes ( $54 \%$ declared themselves to be female, $n=191$; $46 \%$ declared to be male, $n=163$ ), with an average age of 34.96 years ( $\mathrm{SD}=7.388)$, which ranged from 22 to 67 years; $46 \%(n=163)$ had a postgraduate degree, and $45.5 \%(n=161)$ had a university-level degree; $63 \%(n=223)$ were married or in a stable relationship; $33.9 \%$ were in analyst positions; $31.9 \%$ were salespeople, consultants, or traders; $19.8 \%$ were in leadership positions; the current average length of service was 5.59 years $(\mathrm{SD}=5.686)$, ranging from 0 (less than a year) to 30 years, with $20.6 \%$ working less than a year in that 
workplace, $13.6 \%$ working 2 years, and $9.6 \%$ working 1 year $-58.8 \%$ totalled people who had less than 6 years of service in their current job.

\section{Measures}

In this study, the socio-demographic questionnaire and the Fear of COVID-19 Scale (FCV19S) were administered.

Socio-demographic Questionnaire This is developed by the authors in order to ascertain socio-demographic data, such as sex, age, educational level, location, position in the company, and length of service in the current job, for example.

Fear of COVID-19 Scale (FCV-19S) This is developed by Ahorsu et al. (2020) and applied to 717 Iranian participants $(\alpha=0.82)$; this is a unidimensional instrument composed of 7 statements about symptoms of fear in relation to COVID-19, which must be evaluated using a 5-point Likert scale, ranging from 1 to 5 , in which 1 is "strongly disagree", 2 is "disagree", 3 is "neither agree nor disagree", 4 is "agree", and 5 is "strongly agree"; the total score is calculated by adding the score for each item, ranging from 7 to 35 , and the higher the score, the greater the fear of COVID-19 (Ahorsu et al. 2020).

\section{Procedures and Ethics}

This study was approved by the National Research Ethics Commission of Brazil (CAAE 31003620.0.0000.5407) and occurred according to guidelines on the cross-cultural adaptation process proposed by Herdman et al. (1998) and by Beaton et al. (2000): translation of the items from the source language (English) into the target language (Portuguese) by a pair of independent bilinguals (T1 and T2); synthesis of translations; back-translation from the target language (Portuguese) to the source language (English), made by four independent bilinguals (BT1, BT2, BT3, and BT4); semantic validation by two independent experts and a final consensus; and data collection through the experimental application of the scale and the sociodemographic questionnaire in volunteers, after reading and accepting the Free, Prior and Informed Consent (FPIC). The instruments were computerised through the Google Forms platform, and the application was made individually online. The link to answer it was sent to companies that forwarded it to employees. Approximately 600 workers received the link, as informed by the companies, and 354 responses were returned, so the adherence rate was close to $59 \%$. Therefore, the sample was defined by snowball sampling. The participant's confidentiality and anonymity was guaranteed.

\section{Data Analysis}

The adequacy of the data to the assumptions of the factor analysis was calculated using the Kaiser-Meyer-Olkin (KMO) and Bartlett's sphericity tests. Exploratory factor analysis (EFA) was performed in order to verify the instrument's structure after cultural adaptation, as well as the calculation of Cronbach's alpha (precision indexes) to ascertain its internal consistency. The maximum likelihood method was used to estimate the parameters in the EFA, after verification and ratification of the normality of the data distribution. Confirmatory factor 
analysis (CFA) was performed in order to confirm the structure of the instrument. The model fit was examined using fit indices, such as the goodness of fit index (GFI), chi-squared test $\left(\chi^{2}\right)$, degrees of freedom (df), root mean square error of approximation (RMSEA), confirmatory fit index (CFI), normed fit index (NFI), and Tucker-Lewis index (TLI). A good model should have the following characteristics: GFI and CFI $>0.90$, NFI and TLI $>0.95$, and RMSEA $<0.08$ (Hair et al. 2013). All analyses were conducted using the IBM SPSS Statistics and IBM SPSS Amos programs.

\section{Results}

The Brazilian version of the FCV-19S was translated as "Escala de Medo da COVID-19". The averages of responses and standard deviations for each of the seven items that made up the scale, after application to the 354 participants, are described in Table 1. The average sum of all items was $15.76(\mathrm{SD}=6.216$; 95\% $\mathrm{CI}=15.11-16.41$; skewness $=0.814$; kurtosis $=0.226$ ). Distributions with skewness and kurtosis between the \pm 2 range were considered normal (Winter et al. 2020).

EFA were performed using the maximum likelihood extraction method. The Kaiser-MeyerOlkin (KMO) sampling adequacy test resulted in 0.881, and Bartlett's sphericity test was significant $\left(\chi^{2}=1260.333, \mathrm{df}=21, p<0.001\right)$. All diagonal values of the anti-imaging test were greater than 0.50 , and the commonality of the items ranged from 0.421 to 0.667 (Table 1). The Brazilian FCV-19S appeared to have a unidimensional structure. The unifactorial instrument showed a total explained variance of $53.66 \%$, with factorial loads ranging from 0.649 to 0.817 (Table 1$)$ and a significant adjustment quality test $\left(\chi^{2}=122.946\right.$, $\mathrm{df}=14, p<0.001)$. Since it is a measure whose structure was composed of a single factor (unidimensional), the solution cannot be rotated. Cronbach's alpha (precision index) was 0.883 , confirming the instrument's internal consistency.

CFA was performed to confirm the structure of the Brazilian FCV-19S. Two unidimensional models with the seven items were tested. In model 1, there were no correlated error variances, resulting in acceptable indices, with the exception of RMSEA, which presented a value above $0.08(\mathrm{GFI}=0.900 ; \mathrm{CFI} 0.912 ; \mathrm{NFI}=0.902 ; \mathrm{TLI}=0.868 ; \mathrm{RMSEA}=0.149[90 \%$ CI: $0.126 ; 0.174])$. The modification indices suggested the presence of notable error covariance within the cluster of item 1 ("I am most afraid of coronavirus-19"), item 2 ("It makes me uncomfortable to think about coronavirus-19"), and item 5 ("When watching news and stories about coronavirus-19 on social media, I become nervous or anxious") and item 1 and item 4 (“I am afraid of losing my life because of coronavirus-19”) (Fig. 1).

Table 1 Descriptive analysis of the items of the Brazilian FCV-19S

\begin{tabular}{|c|c|c|c|c|c|c|c|}
\hline Item & $M$ & $\mathrm{SD}$ & CI & $h^{2}$ & FL & Skewness & Kurtosis \\
\hline Item 1 & 2.84 & 1.270 & $2.71-2.97$ & 0.467 & 0.684 & 0.116 & -0.985 \\
\hline Item 2 & 3.03 & 1.266 & $2.90-3.16$ & 0.421 & 0.649 & -0.095 & -0.998 \\
\hline Item 3 & 1.47 & 0.821 & $1.38-1.55$ & 0.510 & 0.714 & 1.689 & 1.865 \\
\hline Item 4 & 2.45 & 1.314 & $2.31-2.58$ & 0.460 & 0.678 & 0.558 & -0.826 \\
\hline Item 5 & 2.65 & 1.214 & $2.52-2.78$ & 0.571 & 0.755 & 0.325 & -0.872 \\
\hline Item 6 & 1.56 & 0.930 & $1.47-1.66$ & 0.659 & 0.812 & 1.586 & 1.371 \\
\hline Item 7 & 1.73 & 1.095 & $1.62-1.85$ & 0.667 & 0.817 & 1.428 & 1.079 \\
\hline
\end{tabular}

$C I$ confidence interval, $F L$ factorial loads, $h^{2}$ communalities, $M$ mean, $S D$ standard deviation 


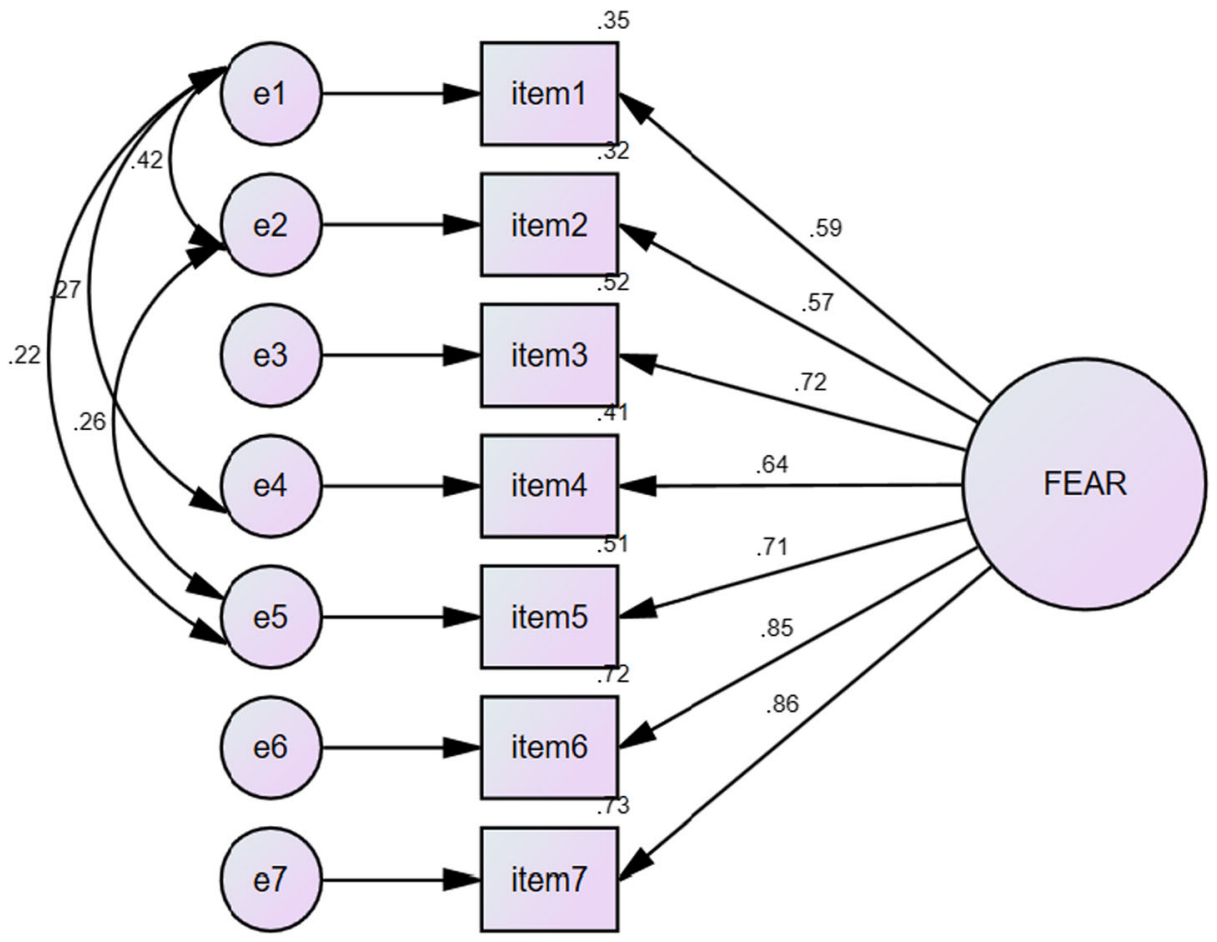

Fig. 1 Model 2: CFA of the Brazilian FCV-19S

These four items (1, 2, 4, and 5) correspond to emotional responses to COVID-19, according to the results of Reznik et al. (2020). So, in model 2 (Fig. 1), when the error variances of these items were correlated, RMSEA decreased substantially, resulting in good indices $(\mathrm{GFI}=0.982$; CFI 0.990; NFI $=0.983$; TLI $=0.979$; RMSEA $=0.059$ [90\% CI: 0.025 ; $0.092]$ ), with high factor loads (range 0.57 to 0.86 ), confirming the psychometric performance of the scale and the instrument's structure.

\section{Discussion}

The current study presented the adaptation of the Fear of COVID-19 Scale (FCV-19S) and its validation for the Brazilian context (Appendix). The version was translated as "Escala de Medo da COVID-19" and maintained the robustness of the psychometric properties, with good scores in the EFA, in the calculation of Cronbach's alpha $(\alpha=0.88)$, satisfactory indexes of adjustments of the model in the CFA, and good factorial loads of the items (range 0.57 to 0.86 ).

In effect, the present study achieved the two main objectives: (1) adaptation and validation of the Brazilian version of the scale and (2) confirmation of the instrument structure, corroborating and complementing previous studies (Ahorsu et al. 2020; Alyami et al. 2020; Bitan et al. 2020; Reznik et al. 2020; Sakib et al. 2020; Satici et al. 2020; Soraci et al. 2020; Tsipropoulou et al. 2020; Winter et al. 2020). We conclude, therefore, that this instrument is considered appropriate for application in the current context, which may contribute substantially to help with diagnoses and treatments aimed at the mental health of the Brazilian 
population currently, in addition to supporting public policies and programs to deal with the psychological and social impacts resulting from the pandemic of COVID-19.

This study has theoretical and practical implications. With regard to theoretical contributions, the instrument was adapted and validated for the Brazilian context, which can be applied in research on the pandemic caused by the new coronavirus SARS-CoV-2 (Appendix). Also, it has practical clinical implications; thus, mental health professionals can use this instrument to complement diagnoses and develop more effective conducts for the prevention and treatment of psychological disorders resulting from the current pandemic context of COVID-19.

Finally, a practical social implication needs to be considered and analysed carefully. Outbreaks of infectious diseases can cause fear of contracting them and, therefore, contaminate other people, as has happened in the past, during the SARS and MERS epidemics, for example. Some of the effects of fear of an infectious disease are discrimination, isolation, and stigmatisation. As the COVID-19 pandemic is ongoing, a wave of fear and worry in the society has arisen, and several communities seem to develop a new by-product of discrimination, that is, mutual discrimination within the Asian/Chinese societies (Lin 2020), for example. Therefore, this study points out that, in addition to the preventive/protective guidelines and methods released by public health authorities, it is essential that companies, institutions, public entities, governments, health professionals, and the general population promote actions aimed at combating discrimination and stigmatisation of people confirmed with the disease or with suspicion or of specific groups in which there was a large concentration of cases. For this reason, it is important to develop programs that can combat the misinformation, stigma, and fear of COVID-19 (Lin 2020). Moreover, people with exacerbated fear may develop distorted perceptions about the real risks of the disease, overburdening health services or causing stocking behaviours, creating a lack of certain products for those in need. These social consequences that the fear of COVID-19 can cause should not be ignored and neglected, and this instrument can help to measure it.

\section{Conclusion}

This study outlines the Brazilian translation and validation of the Fear of COVID-19 Scale (FCV19S). Our findings support, corroborate, and complement previous studies of psychometric properties, validity, and reliability of this scale in samples from other countries. We concluded that Brazilian FCV-19S (Appendix) is a psychometrically appropriate scale to assess the fear of COVID-19 in the general Brazilian population, applicable in Portuguese speakers.

\section{Limitations}

The limitations of this study include the restricted scope of participants; the sample was selfselected, with a modest size, and was not necessarily representative of the general population of Brazil; no formal diagnosis of mood disorders was undertaken; it was assessed using a selfreported measure, which has the risk of source bias, and social desirability factors might have influenced participant responses to the questionnaire; snowball sampling weakens the generalisation of the findings; so it is recommended that further research be performed using this scale, in order to complement the results found, expanding the sample to people from other regions of the country, on bigger and more representative samples of Brazilian participants. 


\section{Compliance with Ethical Standards}

Conflict of Interest The authors declare that they have no conflict of interest.

Ethical Approval All procedures performed in this study involving human participants were in accordance with the ethical standards of the research team's organisational ethics board and with the 1975 Declaration of Helsinki.

Informed Consent Informed consent was obtained from all participants.

\section{Appendix. Brazilian version of the Fear of COVID-19 Scale}

\section{Escala de Medo da COVID-19}

Por favor, leia cuidadosamente cada uma das afirmações abaixo e selecione o número $(1,2$, 3,4 , ou 5) que melhor representa o quanto você concorda ou discorda com a afirmativa, indicando como você se sentiu durante a última semana, incluindo hoje, em decorrência da pandemia do novo coronavírus (COVID-19), conforme escala a seguir:

Discordo totalmente $=[1][2][3][4][5]=$ Concordo totalmente

\begin{tabular}{|c|c|c|c|c|c|c|}
\hline Item & Questão & & & scal & & \\
\hline 1 & Atualmente, o que eu mais tenho medo é do coronavírus (COVID-19). & 1 & 2 & 3 & 4 & 5 \\
\hline 2 & Pensar no coronavírus (COVID-19) me deixa desconfortável. & 1 & 2 & 3 & 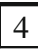 & 5 \\
\hline 3 & Minhas mãos ficam úmidas quando penso no coronavírus (COVID-19). & 1 & 2 & 3 & 4 & 5 \\
\hline 4 & Tenho medo de perder a vida por causa do coronavírus (COVID-19). & 1 & 2 & 3 & 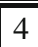 & $\overline{5}$ \\
\hline 5 & $\begin{array}{l}\text { Ao ver notícias e histórias sobre o coronavírus (COVID-19) nas redes sociais e } \\
\text { televisão, fico nervoso ou ansioso. }\end{array}$ & 1 & 2 & 3 & 4 & 5 \\
\hline 6 & $\begin{array}{l}\text { Estou com problemas no sono porque estou preocupado em ser contaminado com } \\
\text { o coronavírus (COVID-19). }\end{array}$ & 1 & 2 & 3 & 4 & 5 \\
\hline 7 & $\begin{array}{l}\text { Meu coração dispara ou palpita quando penso que posso ser contaminado com o } \\
\text { coronavirus (COVID-19). }\end{array}$ & 1 & 2 & 3 & 4 & 5 \\
\hline
\end{tabular}

\section{References}

Ahorsu, D. K., Lin, C.-Y., Imani, V., Saffari, M., Griffiths, M. D., \& Pakpour, A. H. (2020). The Fear of COVID-19 Scale: development and initial validation. International Journal of Mental Health and Addiction, 1-9. https://doi.org/10.1007/s11469-020-00270-8.

Alyami, M., Henning, M., Krägeloh, C. U., \& Alyami, H. (2020). Psychometric evaluation of the Arabic version of the Fear of COVID-19 Scale. International Journal of Mental Health and Addiction, 1-14. https://doi. org/10.1007/s11469-020-00316-x.

Barlow, D. H. (2000). Unraveling the mysteries of anxiety and its disorders from the perspective of emotion theory. American Psychologist, 55(11), 1247-1263. https://doi.org/10.1037/0003-066X.55.11.1247.

Beaton, D. E., Bombardier, C., Guillemin, F., \& Ferraz, M. B. (2000). Guidelines for the process of cross-cultural adaptation of self-report measures. Spine, 25(24), 3186-3191. https://doi.org/10.1097/00007632200012150-00014.

Bitan, D. T., Grossman-Giron, A., Bloch, Y., Mayer, Y., Shiffman, N., \& Mendlovic, S. (2020). Fear of COVID19 scale: psychometric characteristics, reliability and validity in the Israeli population. Psychiatry Research, 289(113100), 1-22. https://doi.org/10.1016/j.psychres.2020.113100. 
Clarke, L. A., \& Watson, D. (1995). Constructing validity: basic issues in objective scale development. Psychological Assessment, 7(3), 309-319. https://doi.org/10.1037/1040-3590.7.3.309.

Comrey, A. L. (1988). Factor-analytic methods of scale development in personality and clinical psychology. Journal of Consulting and Clinical Psychology, 56(5), 754-761. https://doi.org/10.1037/0022-006 X.56.5.754.

Guadagnoli, E., \& Velicer, W. F. (1988). Relation of sample size to the stability of component patterns. Psychological Bulletin, 103(2), 265-275. https://doi.org/10.1037/0033-2909.103.2.265.

Hair Jr., J. F., Black, W. C., Babin, B. J., \& Anderson, R. E. (2013). Multivariate data analysis (7th ed.). Nova Jersey: Pearson Education Limited.

Harper, C. A., Satchell, L. P., Fido, D., \& Latzman, R. D. (2020). Functional fear predicts public health compliance in the COVID-19 pandemic. International Journal of Mental Health and Addiction, 1-14. https://doi.org/10.1007/s11469-020-00281-5.

Herdman, M., Fox-Rushby, J., \& Badia, X. (1998). A model of equivalence in the cultural adaptation of HRQoL instruments: the universalist approach. Quality of Life Research, 7(4), 323-335. https://doi.org/10.1023 /A:1008846618880.

Johns Hopkins University. (2020). COVID-19 dashboard by the Center for Systems Science and Engineering (CSSE). Retrieved May 30, 2020, from https://coronavirus.jhu.edu/map.html.

Lin, C.-Y. (2020). Social reaction toward the 2019 novel coronavirus (COVID-19). Social Health and Behavior, 3(1), 1. https://doi.org/10.4103/SHB.SHB.

Ministry of Health of Brazil. (2020). Painel Coronavírus [Coronavirus panel]. Retrieved June 21, 2020, from https://covid.saude.gov.br/.

Ornell, F., Schuch, J. B., Sordi, A. O., \& Kessler, F. H. P. (2020). "Pandemic fear” and COVID-19: mental health burden and strategies. Brazilian Journal of Psychiatry, 42(3), 1-5. https://doi.org/10.1590/1516-4446-2020-0008.

Pakpour, A. H., \& Griffiths, M. D. (2020). The fear of COVID-19 and its role in preventive behaviors. Journal of Concurrent Disorders, 2(1), 58-63 Retrieved from https:/concurrentdisorders.ca/2020/04/03/the-fear-ofcovid-19-and-its-role-in-preventive-behaviors/.

Reznik, A., Gritsenko, V., Konstantinov, V., Khamenka, N., \& Isralowitz, R. (2020). COVID-19 fear in Eastern Europe: validation of the Fear of COVID-19 Scale. International Journal of Mental Health and Addiction. https://doi.org/10.1007/s11469-020-00283-3.

Sakib, N., Bhuiyan, A. K. M. I., Hossain, S., Al Mamun, F., Hosen, I., Abdullah, A. H., et al. (2020). Psychometric validation of the Bangla Fear of COVID-19 Scale: confirmatory factor analysis and Rasch analysis. International Journal of Mental Health and Addiction, 1-22. https://doi.org/10.1007/s11469-020-00289-x.

Satici, B., Gocet-Tekin, E., Deniz, M. E., \& Satici, S. A. (2020). Adaptation of the Fear of COVID-19 Scale: its association with psychological distress and life satisfaction in Turkey. International Journal of Mental Health and Addiction, 1-9. https://doi.org/10.1007/s11469-020-00294-0.

Soraci, P., Ferrari, A., Abbiati, F. A., Del Fante, E., De Pace, R., Urso, A., \& Griffiths, M. D. (2020). Validation and psychometric evaluation of the Italian version of the Fear of COVID-19 Scale. International Journal of Mental Health and Addiction, 1-10. https://doi.org/10.1007/s11469-020-00277-1.

Steimer, T. (2002). The biology of fear- and anxiety-related behaviors. Dialogues in Clinical Neuroscience, 4(3), 231-249 Retrieved from https:/www.ncbi.nlm.nih.gov/pmc/articles/PMC3181681/.

Strongman, K. T. (1996). The psychology of emotion: theories of emotion in perspective. New York: Wiley.

Tsipropoulou, V., Nikopoulou, V. A., Holeva, V., Nasika, Z., Diakogiannis, I., Sakka, S., et al. (2020). Psychometric properties of the Greek version of FCV-19S. International Journal of Mental Health and Addiction, 1-10. https://doi.org/10.1007/s11469-020-00319-8.

Winter, T., Riordan, B. C., Pakpour, A. H., Griffiths, M. D., Mason, A., Poulgrain, J. W., \& Scarf, D. (2020). Evaluation of the English version of the Fear of COVID-19 Scale and its relationship with behavior change and political beliefs. International Journal of Mental Health and Addiction, 1-11. https://doi.org/10.1007 /s11469-020-00342-9.

Xiang, Y.-T., Li, W., Zhang, Q., Jin, Y., Rao, W.-W., Zeng, L.-N., Lok, G. K. I., Chow, I. H. I., Cheung, T., \& Hall, B. J. (2020a). Timely research papers about COVID-19 in China. The Lancet, 395(10225), 684-685. https://doi.org/10.1016/S0140-6736(20)30375-5.

Xiang, Y.-T., Yang, Y., Li, W., Zhang, L., Zhang, Q., Cheung, T., \& Ng, C. H. (2020b). Timely mental health care for the 2019 novel coronavirus outbreak is urgently needed. The Lancet Psychiatry, 7(3), 228-229. https://doi.org/10.1016/S2215-0366(20)30046-8.

Yao, H., Chen, J.-H., \& Xu, Y.-F. (2020). Patients with mental health disorders in the COVID-19 epidemic. The Lancet Psychiatry, 7(4), e21. https://doi.org/10.1016/S2215-0366(20)30090-0.

Publisher's Note Springer Nature remains neutral with regard to jurisdictional claims in published maps and institutional affiliations. 